07

\title{
Изменение характеристик полупроводниковых структур СВЧ-усилителей под воздействием импульсного лазерного излучения
}

\author{
(C) В.Н. Пашенцев \\ Национальный исследовательский ядерный университет „МИФИ“, \\ 115409 Москва, Россия \\ e-mail: pashentsev2001@mail.ru
}

Поступило в Редакцию 21 февраля 2021 г.

В окончательной редакции 10 июня 2021 г.

Принято к публикации 12 июня 2021 г.

Исследовано действие импульсного лазерного излучения на изменение параметров полупроводниковых структур полевых транзисторов с затвором Шотки с рабочим диапазоном частот $1.5-8 \mathrm{GHz}$ и интегральных усилителей с рабочим диапазоном частот $0.4-6 \mathrm{GHz}$. Лазерное излучение с длительностью импульса $25 \mathrm{~ns}$, падающее на кристалл транзистора, создает импульсный фототок. Показано, что амплитуда импульсного фототока в три раза превышает рабочий ток транзистора. Измерены вольт-амперные характеристики полевого транзистора в режиме импульсного лазерного излучения. Исследована зависимость амплитуды импульсного фототока в полупроводниковых структурах от мощности лазерного излучения для длин волн 1.06 и $0.53 \mu \mathrm{m}$. Показано, что в результате воздействия импульсного лазерного излучения на полупроводниковые структуры происходит кратковременный срыв усиления высокочастотного сигнала на выходе усилителя.

Ключевые слова: лазерное излучение, транзистор, СВЧ-усилитель, фототок, вольт-амперная характеристика.

DOI: $10.21883 / J T F .2021 .11 .51533 .43-21$

\section{Введение}

Поток электромагнитного излучения и заряженных частиц высокой энергии в космическом пространстве, падающий на космический аппарат, может приводить к сбоям в работе электронных модулей или к кратковременной потере их функций на время прохождения потока ионизирующего излучения $[1,2]$. Под действием гамма-квантов, заряженных и нейтральных частиц, проходящих через полупроводник, происходит образование электронно-дырочных пар $[3,4]$. Их количество зависит не столько от вида излучения, сколько от энергии, поглощенной в полупроводнике. Аналогичный эффект образования электронно-дырочных пар возникает под действием лазерного излучения, непосредственно падающего на полупроводниковые структуры. Электронная аппаратура проходит тестирование различными видами ионизирующих излучений. Для этих целей используются источники ионизирующих излучений: электронные и ионные ускорители, источники мощного тормозного излучения электронов, радиоизотопные источники, помещенные в защитные экраны и ядерные реакторы.

Импульсное ионизирующее лазерное излучение также применяется для оперативного тестирования электронной аппаратуры, так как при его поглощении в полупроводниковых структурах возникает импульс фототока, который генерируется в результате образования электронно-дырочных пар. Тестировать можно как уже изготовленные полупроводниковые приборы, у которых отсутствует верхняя часть корпуса над кристаллом, так и структуры на полупроводниковых пластинах с применением зондовых методов на самых ранних стадиях изготовления электронных приборов $[5,6]$.

Для установления связи между ионизацией эмитирующим лазерным излучением и высокоэнергетичным рентгеновским излучением можно применять расчетный метод и метод калибровки тормозным излучением, генерируемым импульсным электронным ускорителям с энергией частиц в сотни $\mathrm{keV}$. В расчетном методе необходимо учитывать зонную структуру полупроводникового соединения, отражение лазерного излучения от поверхности, его однородность и глубину поглощения, эффективность рождения электронно-дырочных пар при заданной энергии квантов лазерного излучения [5-7]. В настоящей работе расчетный метод осложняется тем, что необходимо учитывать также двухфотонный механизм поглощения лазерного излучения на длине воны $1.06 \mu \mathrm{m}$ в широкозонной полупроводниковой структуре GaAs. На импульсных электронных ускорителях также могут проводиться экспериментальные исследования и калибровочные измерения с целью нахождения коэффициента эквивалентности между интенсивностью лазерного излучения и мощностью дозы высокоэнергетического излучения.

Применение лазеров в лабораторных условиях значительно упрощает процесс тестирования и снижает трудоемкость испытаний электронной аппаратуры, сокращает сроки испытаний и повышает точность измерений изза низкого уровня импульсных помех по сравнению с помехами мощных импульсных ускорителей электро- 
$a$

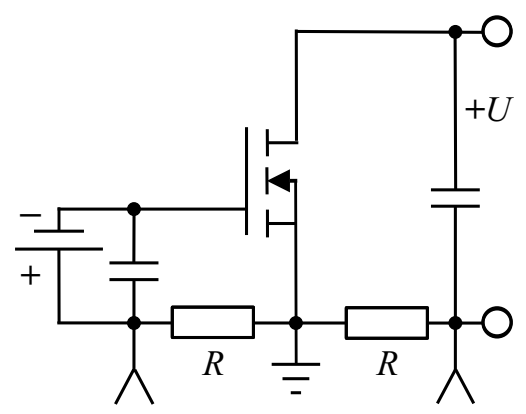

$b$

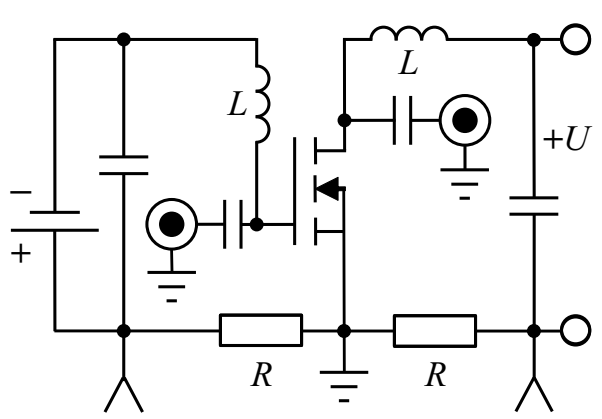

C

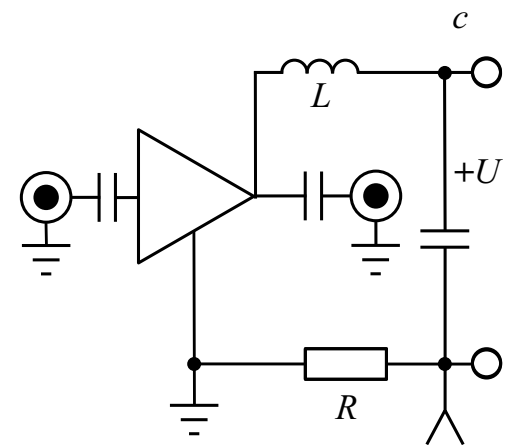

Рис. 1. Схемы измерения фототока: $a-$ полевого транзистора, $b-$ фототока и СВЧ-сигнала транзисторного усилителя, $c$ - фототока тока и СВЧ-сигнала интегрального усилителя.

нов и ионов [7-9]. Целью настоящей работы является экспериментальное исследование влияния импульсного лазерного ионизирующего излучения на характеристики GaAs транзисторных усилителей.

\section{1. Методика эксперимента}

Область рабочих частот современной СВЧ-электроники смещается в область десятков $\mathrm{GHz}$ и выше. В настоящее время применяются полупроводниковые соединения с высокой подвижностью электронов, что значительно отличает их от полупроводниковых структур на основе $\mathrm{Si}, \mathrm{SiC}, \mathrm{SiGe}, \mathrm{GaN}$. Для производства СВЧ-усилителей широко используются структуры на основе соединения GaAs или другие полупроводниковые соединения $\mathrm{A}_{3} \mathrm{~B}_{5}$, представляющие наибольший интерес для современной электроники. Для экспериментальных исследований использовались GaAs MESFET (metal-semiconductor field-effect transistor) с затвором Шотки и интегральные усилители, выполненные на основе псевдоморфных транзисторов с высокой подвижностью электронов (pHЕМТ). Полевые транзисторы имели следующие характеристики: рабочий диапазоном частот $1.5-8 \mathrm{GHz}$, усиление $23 \mathrm{~dB}$, напряжение затвор-исток равно $-0.6 \mathrm{~V}$, напряжение сток-исток было $5 \mathrm{~V}$, ток стока составлял $25 \mathrm{~mA}$. Интегральные усилители с рабочим диапазоном частот $0.4-6 \mathrm{GHz}$ и усилением $14 \mathrm{~dB}$ имели напряжение питания $5 \mathrm{~V}$. В экспериментальных исследованиях использовались СВЧ-генератор сигналов с частотой $1 \mathrm{GHz}$ и осциллограф DSO9404A. Работа выполнена с применением лазерной установки „Радон$8 \mathrm{M}$ “, работающей в основном на гармонике с длиной волны $1.06 \mu \mathrm{m}$ или второй гармонике $0.53 \mu \mathrm{m}$. Максимальная энергия лазерного импульса на образце составляла $150 \mathrm{~mJ}$, длительность импульса лазерного излучения по основанию равна $25 \mathrm{~ns}$.

Излучение Nd:YAG-лазера было направлено сверху на лицевую сторону полупроводникового кристалла полевого транзистора или интегрального усилителя. На поглощение излучения оказывало влияние расположение контактных металлизированных площадок на кристалле, что является особенностью данного метода исследований. При низкой средней мощности лазера, работающего в режиме однократных импульсов с большим интервалом между импульсами, нагрев металлических контактов не наблюдался. Особенность применения лазера с двумя модами излучения состояла в том, что энергия квантов излучения с длиной волны $1.06 \mu \mathrm{m}$ была меньше ширины запрещенной зоны полупроводникового соединения GaAs. Поэтому образование электроннодырочных пар в полупроводнике было обусловлено двухфотонным поглощением лазерного излучения. В инфракрасной области спектра прозрачность полупроводниковой структуры выше, чем в области видимого диапазона, поэтому глубина проникновения излучения и однородность поглощения по глубине была выше, чем для излучения с длинной волны $0.53 \mu \mathrm{m}$. С другой стороны, при лазерном излучении в области видимого спектра энергия квантов была в два раза больше, и она превышала ширину запрещенной зоны полупроводникового соединения. Эти факторы будут влиять на эффективность образования электронно-дырочных пар, а также на глубину и однородность поглощения лазерного излучения в полупроводнике.

При непосредственном подключении осциллографа к цепям транзисторного усилителя его низкое входное сопротивление $50 \Omega$ будет шунтировать имеющиеся активные и реактивные элементы транзисторного усилителя, что изменит его рабочий режим. Поэтому для измерения токов в цепях усилителя были использованы токоизмерительные резисторы с сопротивлением $2 \Omega$ (рис. 1), которые подключались относительно земли в разрыв цепей источников питания затвора и стока транзистора или в цепь питания интегрального усилителя. Подключение осциллографа к низкоомным сопротивлениям дало возможность существенно уменьшить методическую погрешность измерений, связанную с влиянием низкого входного сопротивления осциллографа на цепь. Применение измерительного резистора $R=2 \Omega$ и включение сопротивления согласования $50 \Omega$ на входе осциллографа дают возможность измерять параметры 
$a$

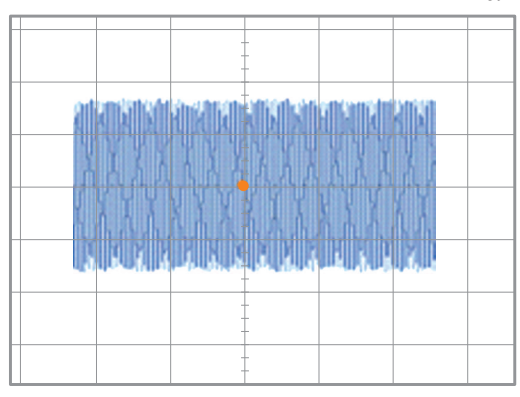

$b$

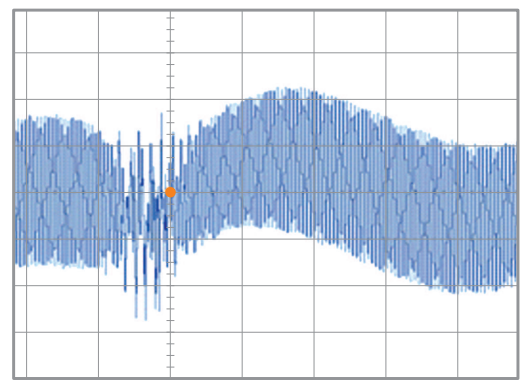

C
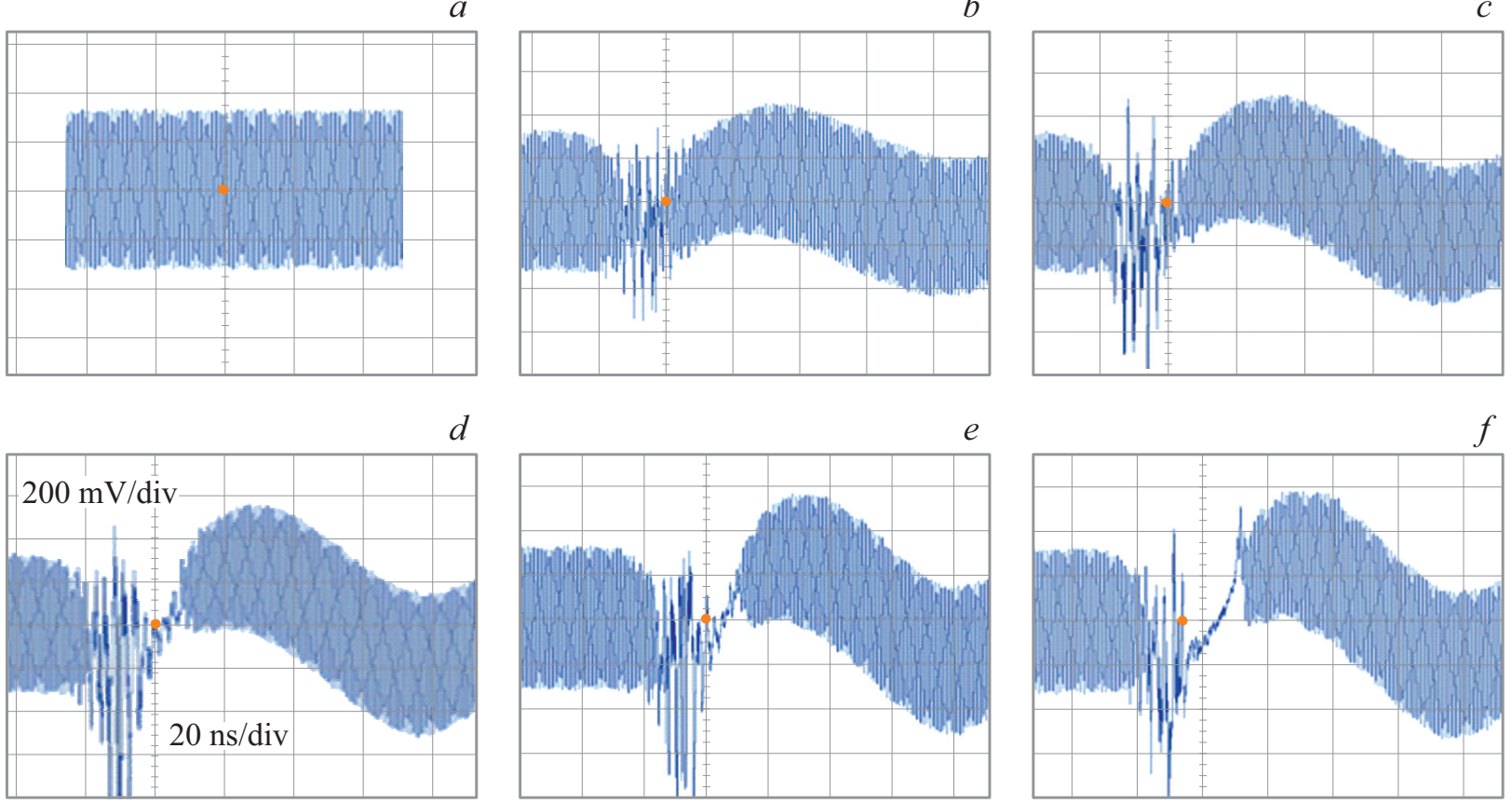

$d$

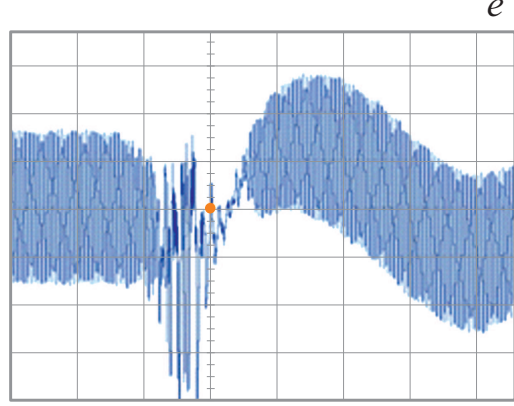

$e$

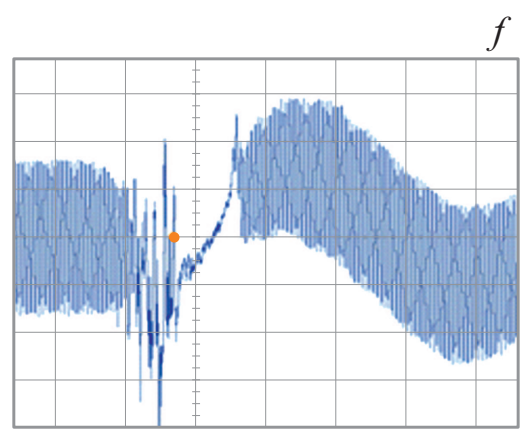

Рис. 2. Изменение формы СВЧ-сигнала при увеличении относительной мощности лазера $P / P_{0}$ с шагом 0.2 в диапазоне $0-1$ : $a-P / P_{0}=0, b-0.2, c-0.4, d-0.6, e-0.8, f-1$.

широкополосных СВЧ-сигналов и импульсов короткой длительности с небольшой погрешностью в единицы процентов. Схема, показанная на рис. 1, $a$, применялась для измерения импульсного фототока в цепях затвора и стока транзистора и для получения вольт-амперных характеристик (BАХ) транзистора. На рис. 1, $b$, с показаны схемы измерения импульса фототока и СВЧсигнала на выходе усилителей. Таким образом, на экране осциллографа можно наблюдать изменение формы СВЧсигнала под действием лазерного излучения синхронно с импульсом фототока. Фототок измерялся при закрытом входе осциллографа, номинальный рабочий ток - при выключенном лазере.

\section{2. Результаты и обсуждение}

\section{1. Влияние импульсного лазерного излучения на усиление сигнала}

Импульсный поток лазерного излучения, направленный непосредственно на поверхность полупроводниковой структуры усилителя (рис. $1, c$ ), приводит к срыву усиления СВЧ-сигнала на выходе усилителя. На рис. 2 показано изменение формы СВЧ-сигнала на выходе интегрального усилителя при увеличении мощности лазерного излучения с длиной волны $\lambda=0.53 \mu \mathrm{m} \mathrm{c}$ шагом $P / P_{0}=0.2$. Под действием импульсного лазерного излучения СВЧ-сигнал прерывается, наблюдаются высокочастотные колебания. После окончания лазерного импульса происходит восстановление амплитуды СВЧсигнала за время, которое превышает длительность

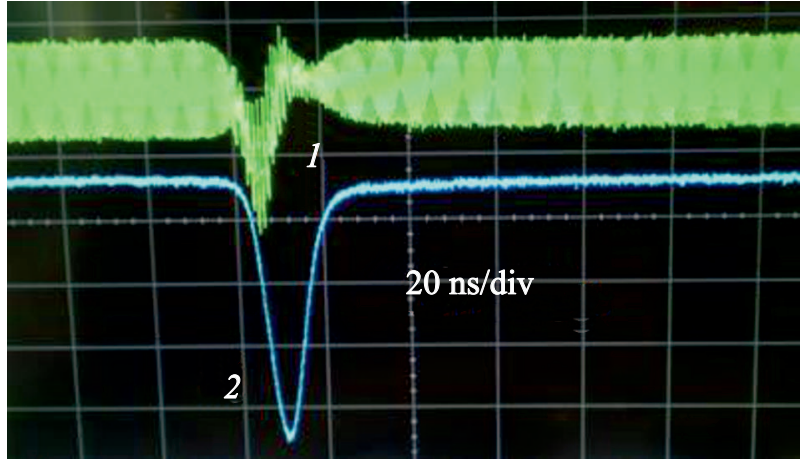

Рис. 3. Осциллограмма сигналов GaAs MESFET усилителя: 1 - СВЧ-сигнал $(0.5 \mathrm{~V} / \mathrm{div}), 2$ импульс фототока $(20 \mathrm{mV} / \mathrm{div})$.

импульса лазера. На восстановление амплитуды СВЧсигнала может оказывать влияние длительность рассасывания электронно-дырочных пар, образовавшихся в результате лазерной ионизации соединения GaAs.

На работу усилителя существенное влияние оказывает импульс фототока, который протекает в полупроводниковой структуре транзисторного усилителя под действием лазерной ионизации. На рис. 3 показаны СВЧ-сигнал на выходе GaAs MESFET усилителя и форма импульса фототока $(\lambda=1.06 \mu \mathrm{m})$ в цепи питания усилителя, измеренные по схеме рис. $1, b$. На фронте импульса фототока происходит резкое уменьшение амплитуды СВЧ-сигнала и затем его кратковременное отсутствие. После завершения импульса лазера сигнал восстанавли- 
вается до значения 0.8-1 амплитуды. Импульс фототока, показанный на рис. 3, является симметричным относительно середины импульса: времена фронта и спада импульса являются практически одинаковыми. Протекание импульсного фототока в транзисторе прекращалось после окончания ионизирующего лазерного излучения. Длительность импульса фототока не изменялась при изменении мощности лазера, изменялась только амплитуда, что свидетельствует об отсутствии накопления заряда в полупроводниковой структуре под действием лазерной ионизации.

Пороговый эффект срыва усиления СВЧ-сигнала при лазерном облучении не наблюдался (рис. 2). Повидимому, при различном уровне мощности лазерного излучения в транзисторе всегда протекает фототок, который влияет на работу транзисторного усилителя.

\section{2. Импульсный фототок полевого транзистора}

Импульс лазерного излучения может различным образом изменять режим работы транзисторного усилителя или не изменять его, если амплитуда импульсного фототока будет значительно меньше рабочего тока транзистора. Поэтому, чтобы оценить уровень воздействия лазерного излучения, были проведены экспериментальные исследования зависимости амплитуды фототока от относительной мощности лазера и зависимость фототока от напряжения питании транзистора в режиме импульсного воздействия лазерного излучения.

Амплитуда импульса фототока GaAs MESFET пропорциональна мощности лазерного излучения (рис. 4). При небольшой относительной мощности лазерного излучения $(\lambda=1.06 \mu \mathrm{m})$ амплитуда фототока возрастает пропорционально количеству поглощенной энергии. На рис. 5, a показана ВАХ транзистора. Амплитуда импульса фототока превышает постоянный рабочий ток транзистора в 3-4 раза. Амплитуда импульса фототока возрастает быстрее по сравнению с ростом рабочего тока транзистора при увеличении напряжения на стоке. Канал полевого транзистора можно представить сопротивлением, которое равно отношению напряжения сток-исток к току стока. При лазерном воздействии на полупроводниковую структуру транзистора сопротивление канала уменьшается почти в три раза. При этом сопротивление канала составляет $50 \Omega$ и оно незначительно зависит от напряжения на транзисторе (рис. $5, b$ ).

По-видимому, структура GaAs транзисторов и изменение их проводимости под действием лазерной ионизации оказывает влияние на амплитуду импульса фототока и соответственно на срыв усиления СВЧсигнала. Для производства MOSFET- и рНЕMT-усилителей используются GaAs-подложки, на которых методом молекулярно-лучевой эпитаксии выращивают слой

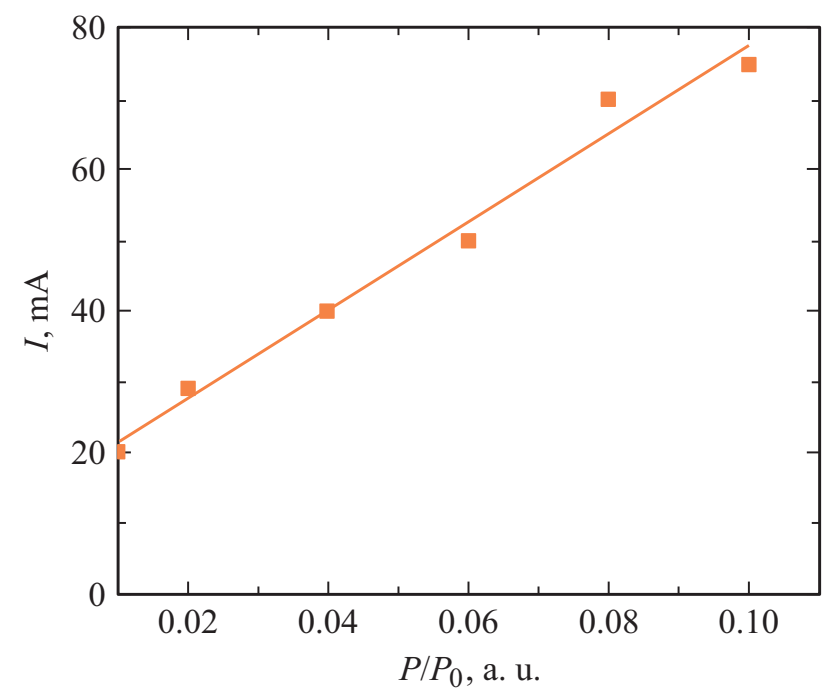

Рис. 4. Зависимость тока стока транзистора от относительной мощности лазерного излучения.

GaAs. B pHEMT-усилителях над этим слоем выращивается тонкий слой другого полупроводника, который вместе с GaAs образует гетеропереход для формирования двумерного электронного газа. Электроны имеют высокую подвижность, поэтому транзисторы на основе GaAs характеризуются высокой рабочей частотой. В обычном состоянии транзистора подложка из материала GaAs имеет низкую проводимость, так как беспримесный материал GaAs из-за широкой прямой запрещенной зоны имеет высокое сопротивление. При этом из-за большой диэлектрической проницаемости емкость слоя подложки на корпус транзистора является небольшой.

При прохождении лазерного излучения через полевой транзистор в его полупроводниковой структуре, находящейся вблизи поверхности, в GaAs-канале транзистора и в массивной подложке генерируются электроннодырочные пары, которые по действием электрического поля дрейфуют к металлическим контактам стока и истока. В результате в области поглощения лазерного излучения протекает фототок. Таким образом, в транзисторе параллельно протекают два тока: рабочий ток в канале полевого транзистора и фототок, который в несколько раз превышает рабочий ток. Так как фототок в подложке связан с ионизирующим лазерным излучением и на него не влияет управляющее напряжением на затворе транзистора, то нарушается режим усиления СВЧ-сигналов. По-видимому, для уменьшения фототока, протекающего в подложке, можно изготовить GaAs-транзистор со структурой, аналогичной структуре транзистора, выполненного по технологии кремний на изоляторе (КНИ). Транзисторы со структурой КНИ имеют высокую радиационную стойкость. Это достигается тем, что тонкий канал транзистора, по которому протекает ток стока, отделен от кремниевой подложки слоем оксида, чтобы электронно-дырочные пары, образованные в мас- 

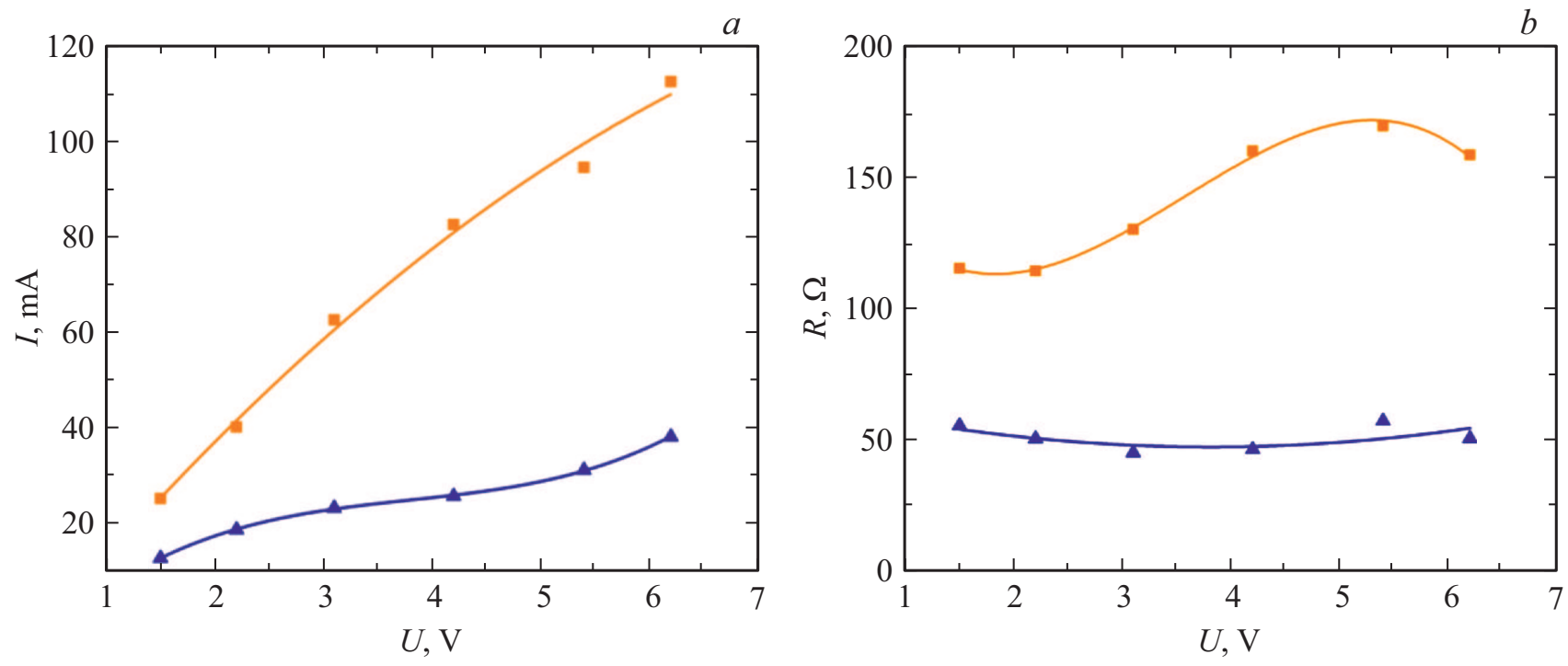

Рис. 5. ВАХ транзистора: $a-$ зависимость тока стока от напряжения исток-сток $(\mathbf{-}-$ фототок стока, $\boldsymbol{\Delta}-$ рабочий ток транзистора); $b$ - зависимость сопротивления канала транзистора от напряжения исток-сток (- сопротивление канала в режиме действия лазерного импульса, $\mathbf{\Delta}$ - сопротивление канала в рабочем режиме в отсутствии лазерного импульса).

сивной кремниевой подложке, не влияли на работу транзистора.

Для уменьшения влияния фототока можно уменьшить толщину GaAs-канала полевого транзистора, чтобы уменьшить объем области ионизации. Также можно расположить изолирующий слой между GaAs-каналом транзистора и GaAs-подложкой, аналогично структуре КНИ транзистора. Тогда электронно-дырочные пары, возникающие в подложке в результате лазерной ионизации, будут слабо влиять на работу транзистора. Изготовление GaAs-транзисторов с промежуточным изолирующим слоем зависит от возможностей технологии молекулярно-лучевой эпитаксии, которая должна обеспечить рост структурированного слоя GaAs на изолирующем слое. Для кремния имеется подходящий оксид $\mathrm{SiO}_{2}$ с параметрами решетки, близкими к кремнию. Для соединения GaAs необходимо выбрать оптимальный состав и структуру соответствующего изолирующего слоя.

\section{3. Импульсные BAX транзистора в режиме лазерного облучения}

BAX полевого транзистора показаны на рис. 6, a. Измерения токов стока и затвора MESFET проводились согласно схеме, показанной на рис. $1, a$. Положительное напряжение на стоке транзистора является рабочей полярностью MESFET с $n$-каналом. При изменении полярности напряжения на обратную полярность (отрицательные напряжения ВАX) фототок стока также изменяет направление на противоположное. При положительном напряжении амплитуда импульсного фототока в несколько раз больше постоянного рабочего тока стока. При отрицательном напряжении фототок меньше постоянного тока стока. При неизменном напряжении на затворе $-0.6 \mathrm{~V}$ амплитуда фототока затвора изменяется незначительно при изменении полярности напряжения сток-исток.

При неизменном напряжении исток-сток $U=5 \mathrm{~V}$ изменялось напряжение на затворе $U_{g}$ (рис. $6, b$ ). В цепи затвора протекал фототок с амплитудой около $15 \mathrm{~mA}$. Амплитуда фототока затвора слабо зависела от напряжения на затворе, в то время как фототок стока увеличивается при открывании канала полевого транзистора при увеличении напряжения от -1.5 до $0 \mathrm{~V}$.

Резкое возрастание тока транзистора под действием импульсного лазерного излучения приводит к кратковременному отсутствию СВЧ-сигнала на выходе усилителя (рис. 3). Это связано с тем, что резкий скачок тока в канале транзистора приводит к изменению режима работы не только транзистора, но и всего усилительного каскада. Рабочая точка транзистора на ВАX смещается в область больших токов, превышающих рабочий ток транзистора в несколько раз. При этом напряжение на транзисторе значительно падает, так как при резком возрастании тока стока увеличивается падение напряжения на индуктивности (или резисторе), установленные в цепи питания усилителя (рис. $1, b, c)$, что приводит к уменьшению напряжения на стоке. Кроме того, сопротивление канала транзистора под действие лазерного излучения значительно уменьшается по сравнению с рабочим режимом. Транзистор работает аналогично электронному ключу с большим током и небольшим напряжением исток-сток, на вход которого поступает СВЧ-сигнал. Поэтому усилительный каскад под действием импульсного лазерного излучения не усиливает сигнал, поступающий на его вход. 

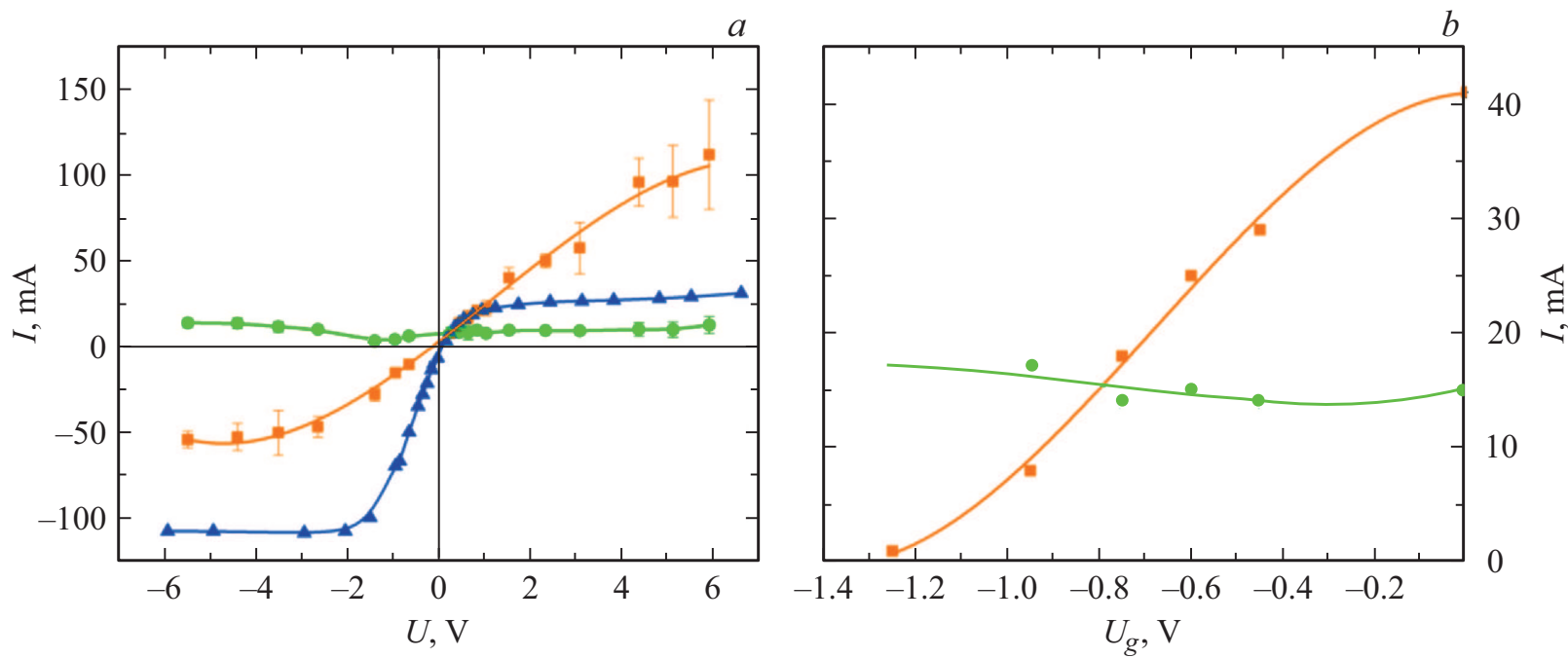

Pис. 6. ВАХ транзистора: $a$ - зависимость тока стока и тока затвора от напряжения исток-сток (匹- фототок стока, $\mathbf{\Delta}$ рабочий ток стока в отсутствии импульсного лазерного излучения, $\bullet-$ фототок затвора); $b-$ зависимость фототоков стока и затвора от напряжения затвор-исток ( - фототок стока, $\bullet-$ фототок затвора).
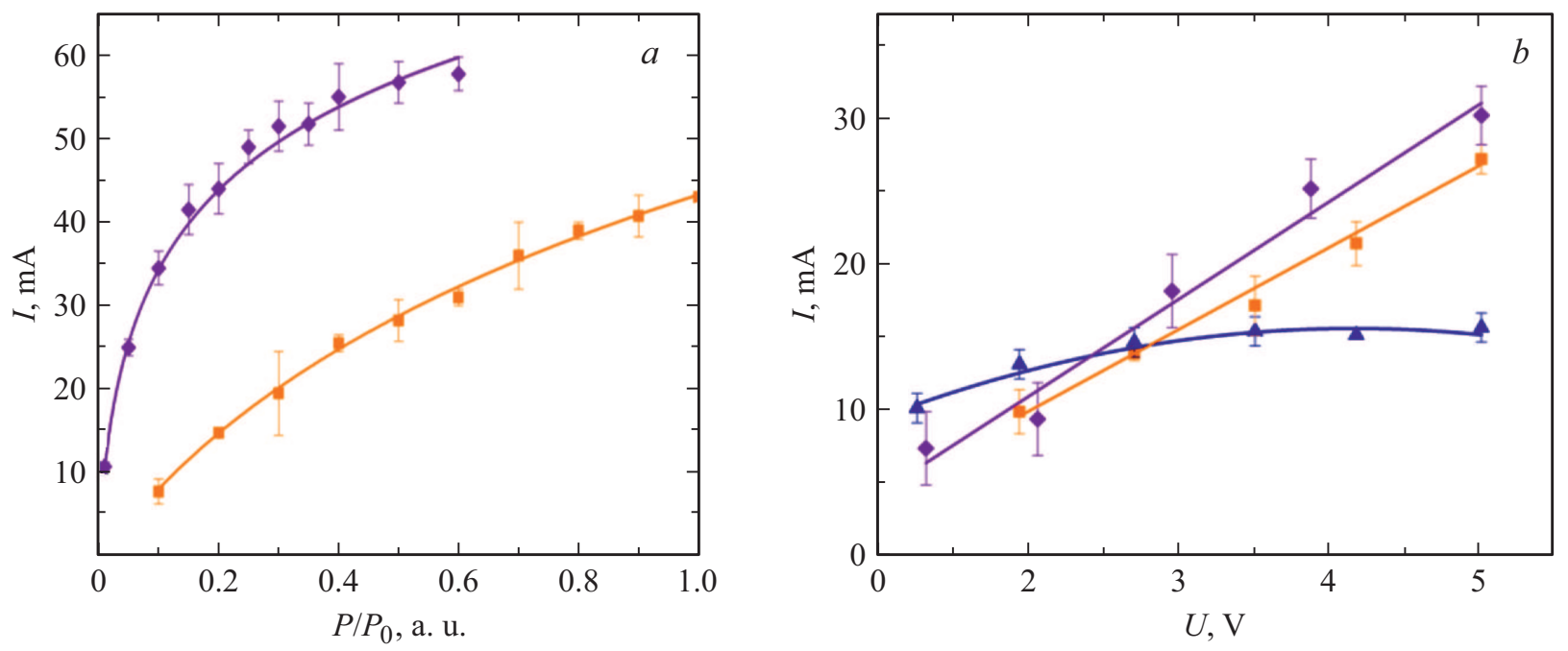

Рис. 7. Амплитуда фототока в цепи питания усилителя: $a$ - зависимость фототока от относительной мощности лазера; $b-$ зависимость фототока от напряжения питания при различных длинах волн $-\lambda=1.06 \mu \mathrm{m}, \downarrow-\lambda=0.53 \mu \mathrm{m},(\boldsymbol{\Delta}-$ зависимость рабочего постоянного тока усилителя от напряжения питания в отсутствии импульсного лазерного излучения).

\section{4. Влияние длины волны лазерного излучения на фототок интегрального усилителя на основе GaAs pHEMT}

Зависимость фототока от относительной мощности лазера (рис. 7,a) и $\mathrm{BAX}$ (рис. 7,b) получены при лазерном излучении с различными длинами волн 1.06 и $0.53 \mu \mathrm{m}$. В области низкой мощности лазера $\left(P / P_{0}<0.2\right)$ амплитуда фототока увеличивается значительно быстрее для меньшей длины волны $\lambda=0.53 \mu \mathrm{m}$, чем при работе лазера на длине волны $\lambda=1.06 \mu \mathrm{m}$ (рис. 7, $a$ ). Вероятно, это связано с высокой эффективностью образования электронно-дырочных пар в полупроводниковой структуре усилителя при увеличенной в два раза энергии квантов лазерного излучения, когда их энергия больше ширины запрещенной зоны полупроводника. Это подтверждает ВАХ усилителя (рис. 7,b). Зависимость амплитуды фототоков от напряжения питания усилителя незначительно отличается при различных длинах волн лазерного излучения. Однако относительная мощность лазера, работающего на длине волны $\lambda=1.06 \mu \mathrm{m}$, составляла $P / P_{0}=0.5$ и была в 5 раз больше по сравнению с относительной мощностью лазера, работающего на длине волны $\lambda=0.53 \mu \mathrm{m}$. Также на высокую эффективность поглощения лазерного излучения в видимом диапазоне спектра может влиять неоднородность выделения энергии по толщине полупроводника, полупроводниковая структура и топология СВЧ-усилителей. 


\section{Заключение}

Тестирование полупроводниковых структур усилителей мощным импульсным лазерным излучением дает возможность выявить особенности усиления СВЧсигналов в режиме лазерной ионизации. Под действием лазерного излучения в цепи питания усилителя протекает импульсный фототок, амплитуда которого в несколько раз превышает рабочий ток усилителя. Импульс фототока изменяет рабочие токи и напряжения транзисторного СВЧ-усилителя, что приводит к кратковременному отсутствию СВЧ-сигнала на его выходе. Фототок создает дополнительное падение напряжения на резисторах и индуктивностях в цепи питания усилителя, задающих режим работы транзистора. Это приводит к значительному уменьшению напряжения на полевом транзисторе. В результате существенно изменяются рабочий режим и ВАХ транзистора. После окончания действия импульса лазерного излучения происходит восстановление амплитуды сигнала. В результате исследования влияния лазерного излучения с различными длинами волн 1.06 и $0.53 \mu \mathrm{m}$ на амплитуду фототока показано, что при работе лазера на длине волны в области видимого спектра требуется меньшая мощность излучения для получения такового же значения амплитуды фототока, как и при облучении полупроводника инфракрасным лазерным излучением.

\section{Конфликт интересов}

Автор заявляет, что у него нет конфликта интересов.

\section{Список литературы}

[1] А.И. Белоус, В.А. Солодуха, С.В. Шведов. Космическая электроника (Техносфера, М., 2015)

[2] U. Scheuermann, U. Schilling. IET Power Electron., 9(10), 2027 (2016). DOI: 10.1049/iet-pel.2015.1003

[3] B.D. Weaver, D. McMorrow, L.M. Cohn. Int. J. High Speed Electron. Syst., 13, 293 (2003).

DOI: $10.1142 / \mathrm{S} 0129156403001624$

[4] H.J. Barnaby. IEEE Tr. Nucl. Sci., 53 (6), 3103 (2006).

[5] Е.А. Тарасова, С.В. Оболенский, С.В. Хазанова, Н.Н. Григорьева, О.Л. Голиков, А.Б. Иванов, А.С. Пузанов. ФТП, 54 (9), 968 (2020). DOI: 10.21883/FTP.2020.09.49841.35 [E.A. Tarasova, S.V. Obolensky, S.V. Khazanova, N.N. Grigoryeva, O.L. Golikov, A.B. Ivanov, A.S. Puzanov. Semiconductors, 54 (9), 1155 (2020). DOI: 10.1134/S1063782620090274]

[6] В.Г. Мокеров, А.А. Кузнецов, Ю.В. Федоров, Е.Н. Енюшкина, А.С. Бугаев, А.Ю. Павлов, Д.Л. Гнатюк, А.В. Зуев, Р.Р. Галиев, Е.Н. Овчаренко, Ю.Н. Свешников, А.Ф. Цацульников, В.М. Устинов. ФТП, 43 (4), 561 (2009).

[7] Д.В. Громов, П.П. Мальцев, С.А. Полевич. ФТП, 50 (2), 223 (2016). [D.V. Gromov, P.P. Maltsev, S.A. Polevich. Semiconductors, 50 (2), 222 (2016).

DOI: $10.1134 / \mathrm{S} 1063782616020093]$
[8] В.В. Елесин. Микроэлектроника, 43 (2), 133 (2014). DOI: $10.7868 / \mathrm{S} 0544126914020057$ [V.V. Elesin. Russ. Microelectron., 43 (2), 139 (2014). DOI: $10.1134 / \mathrm{S} 106373971402005 \mathrm{X}]$

[9] П.К. Скоробогатов, А.Ю. Никифоров, А.Н. Егоров. Микроэлектроника, 44 (1), 12 (2015).

DOI: $\quad 10.7868 /$ S0544126915010081 [P.K. Skorobogatov, A.Yu. Nikiforov, A.N. Egorov. Russ. Microelectron., 44 (1), 8 (2015). DOI: 10.1134/S1063739715010084] 